\title{
Educational Technology and Its Role in Constructing Learning Communities in the Arab Region with Particular Reference to the Egyptian Context - A Descriptive Paper
}

\author{
Mohammad Ahmad Abdeldayem
}

\begin{abstract}
The term "Learning communities" (LCs) represents a fashionable term that has been widely used in the educational literature for at least three decades in USA, Europe and Asia, but not in the Arab region including Egypt . Existence of (LC) in schools and universities helps in overcoming a host of educational problems relating to teaching and learning. Hence, construction of ( $\mathrm{LCs}$ ) in some countries has been achieved in purpose of educational reform. One of the main factors that help very much in constructing ( $\mathrm{LCs}$ ) is the existence of a well prepared educational technology infrastructure and availability of computers in schools and universities. This descriptive paper investigates the positive returns of ( LCs) on education systems in general. At the same time, this paper will elaborate the close relationship between educational technology and establishment of (LCs) in general and in the Egyptian context in particular. This topic has widely been considered on the international level, however it remained absent from the educational scene in the Arab region till now. Establishing learning communities relies heavily on education technology and availability of computers in the educational organizations. Some Arab countries have trials towards supporting their systems of education with an adequate infrastructure of technology but yet not enough to help establishing learning communities.
\end{abstract}

Index Terms-Learning communities, education technology and computers, educational reform, Egyptian context.

\section{INTRODUCTION}

For some while now, it has become clear that there is "a shift in emphasis from learning with the focus on the individual to learning as a part of a community" [1]. The concept and implementation of learning communities as an approach for educational reform started to flourish and be the core of much educational and organizational debates and literature through the last three decades. In its course of development, the learning community concept and implementation have been inspired by practices and experiments of some education systems that could provide their schools with the required technological infrastructure. This has been confirmed by Kilpatrick, Barrett \& Jones when saying, "Information and communication technologies have facilitated the emergence and rapid growth of learning communities whose members interact from remote corners of the globe to form online learning communities" [1].

This notion has been postulated by Janssen, Kyle and Brent [2] but focusing on how technology can help in establishing (LCs) saying that "learning environments" and

Manuscript received May 4, 2014; revised July 4, 2014.

Mohammad Ahmad Abdeldayem is with Comparative Education and Education Administration Department, College of Education, Zagazig University, Egypt (e-mail: abdeldayem666@gmail.com). then "learning communities" have been offered up as models for thinking about instruction, based on the dual platform of technology and the constructivist theory. Rather than forcing students to swallow instructional packages like pills, learning environments are meant to offer students an abundance of resources to explore. Alternatively, learning communities put the emphasis on the whole group, with students collaborating and supporting each other towards various learning goals. In both cases, students are expected to buy into the system and cooperate. Of course, those communities of learners will not be able to widen and enrich their learning except with the existence and spread of education technology, networks, and computers which provide rich, prosperous, and easy to access sources of knowledge and information. Therefore, intensive and extensive use of technology represents one of the main features of creating professional learning communities. Establishing learning communities at any education organization cannot go without the interaction of that aspect amongst members of those communities as one of the most effective factors to achieve the learning outcomes. It is evident that learning communities supported by technology can help to a great extent in achieving dreams of education reformers in the Arab and Egyptian context.

\section{The PROBlematic SituAtion IN EGYPT}

The report of the World Bank about "Education Reform" in the Middle East and North Africa [3] portrayed the problem in the countries of this region as having so many education reform movements focusing on schools construction, recruiting qualified teachers, reconstruction of school curricula and modifications in the evaluation and assessment systems, however education reforms have not yielded the required improvements in their education systems. The World Bank report covered the efforts of reform exerted during the last four decades concluding that "the countries of this region are still suffering from a host of challenges imposed by impact of globalization of education, the increased vitality of knowledge economy, technological support of education systems". Added to those challenges is "the absence of adequate technological infrastructure that may help in establishing connectedness for learning community members" as contemplated by Abdeldayem [4] To guarantee a degree of success for reform, the report invited those countries to focus on changing modes of thinking and behaviors of leaders, teachers, and students who consumes such reforms. Toward this objective, learning communities can provide a new culture that can positively lead the behavior of the school community towards effective and active leadership, teaching, and learning. 
Egypt, like other Arab countries, has had a history with educational reform. The current reform attempts included: Quality Assurance and Accreditation Project, Information and Communication Technology Project and Faculty and Leadership Development Project. All these projects are supported financially by Egyptian government, added to British and American Associations, Arab and Gulf Fund and European Union. However, the outcomes of all of those efforts did not meet the expectations of the Egyptians [5]. Hence, learning communities are now claimed to be one of the most promising initiatives for educational reform in Egypt and other Arab countries.

\section{The MAIN TERM DEFINITION}

The advent of "professional learning communities" to the scene of education in the Arab region requires to re-define the term and try to fit it into the context of this region. In this respect [6], Dufour and Eaker state that: "The school that operates as a professional learning community recognizes that its members must engage in ongoing study and constant practice that characterize an organization committed to continuous improvement...In a professional learning community, educators create an environment that fosters mutual cooperation, emotional support, personal growth as they work together to achieve what they cannot accomplish alone".

So many distinguishing features can identify professional learning communities. Out of these identifiers may be: the belief in and practice of change, collaboration, reflection, technology, dispersed leadership, confirming the roots of success for each other, all learn from and with all, and outcomes-based learning orientation. Referring to leadership [7] Hord and Sommers gave special consideration to the priority of constructing, encouraging, enhancing and sustaining PLCs. They attributed seven elements to effective leadership in these communities known as seven Cs: communication, collaboration, coaching, change, conflict, creativity, and courage. Teachers in PLCs. are having new roles that make them different from teachers in normal communities. Before their being instructors, they are facilitators of learning, coaching students, guiding, leading, even learning with their students.

It is clear that each of the words included in the phrase "Professional Learning Community" has been purposefully chosen. A "Professional" is someone with expertise in a special field, an individual who has not only pursued advanced training to enter the field, but who is also expected to remain current in its evolving knowledge base [8]. The term "Learning " refers to "that active process which occurs overtime, driven by learners around meaningful issues and fueled by rich, diverse and accessible sources of information" And with regard to "Community", it is a group of learners who share the same vision and mission, having a web of diverse relationships and provides the context for the emergence of unpredictable potential [9].

\section{TeChNOlogy Promise For PROFESSIONAL LEARNING COMMUNITIES}

Professional learning communities have become one of the most talked about ideas in education today. Many K-12 schools are working to become professional learning communities in the hope that student learning will improve when adults commit themselves to talking collaboratively about teaching and learning and then take actions that will improve students' learning and achievement [6]. Community has been defined as a group of people who are willing and able to help each other [7]. More definitions have been given to the term by other scholars [6], [8], [9].

Through surveying the concept of this term in the previous literature learning communities can be defined as those communities that are formed on basis of a solid culture of learning. Hence, all members share the same set of values and use all available means and facilities to confirm the roots of learning for every member in the community. These communities are characterized by mutual trust, respect, supportive leadership, team work, openness, caring and outcomes orientation. To achieve its ultimate goal, that is effective and active learning, learning communities should have made use of education technology and its encouraging tools that facilitates, widen, and deepen learning.

It is taken for granted that, with the advent of new communication and information revolution the world has witnessed a parallel revolution in education and learning. Many educationists' visions and dreams that seemed impossible before have become tangible realities nowadays, thanks to engineers and technology architects who helped transfer the dreams into realities. "The new information revolution has enabled academic institutions to provide a flexible and more open learning environment for learners. The convergence of new information technologies such as telecommunications, computers, satellites and fiber optic technologies is making it easier for institutions to implement new forms, styles and approaches of learning" [10].

Just as technology has achieved productivity gains in business and manufacturing, we can expect technology to help with the "work" of education. So now, if a teacher can't respond individually to thirty students at the same time, maybe a computer lesson can provide individual feedback to keep errors private. If the school can't afford a field trip to the museum, then a video or CD-ROM can bring images and presentations to the classroom. If students need access to information, they can search the Web [11]. In learning communities and by virtue of technology, individualized as well as collaborative learning is available. Through computer, individualized learning, instruction and feedback can be achieved, while internet can afford the glue that gather members of the community as students, teachers and parents together in one coherent unit to achieve learning objectives.

It is not only this, but there is a lot for technology to do for reinforcing professional learning communities. Regarding this point, Mcloughlin [12] stated that "Culture and learning are interwoven and inseparable. The use and application of communications technologies can influence the micro culture of the classroom. Increasingly, technologies are being described as cognitive tools, which transform, augment and support cognitive engagement among learners". So, the impact of technology on professional learning communities is not restricted only to materialistic aspects but extended to leave its impact upon mentalities of learners and their culture of learning. 
Above all of this, there are some other returns from technology when supporting learning. In his briefing Schacter [13], after examining some studies about the impact of education technology on learning, concluded the following positive results:

1) Students learn more in less time when they receive computer based instruction.

2) Students like their class more and develop more positive attitudes when their classes include computer based instruction.

3) Students in technology rich environment experienced positive effects on achievement in all major subject areas.

4) Students in such an environment showed increased achievement in pre-school through high education for both regular and special needs children.

5) Students' attitudes toward learning and their own self-concept improved consistently when computers were used for instruction.

\section{Why PROFESSIONAL LEARNING COMMUNITIES FOR ARAB COUNTRIES AND IN PARTICULAR EGYPT}

In answer to the questions "Why learning communities? Why now? Cross [14] gave three reasons: philosophical (because learning communities fit into a changing philosophy of knowledge), research based (because learning communities fit what research tells us about learning), and pragmatic (because learning communities work)". Research results about returns of professional learning communities for learning reveal that "students involved in those communities improve their academic and social achievement" [15]. As highlighted by Collier [16], professional learning communities leave their impact upon staff also in the form of diminished isolation, collaboration among colleagues, increased curricular integration, a fresh approach to academic disciplines, and increased satisfaction with students' learning.

Professional learning communities as theory and practice have got some distinguishing features and characteristics that confirm their sustainability to any education system when implemented. Review of literature on these characteristics show that professional learning communities have the following promising features [17].

1) Shared beliefs, values and vision that guide the behavior of individuals no matter where they work or in what endeavor. The vision is a mental image of what is important for the community and grows while members work together overtime.

2) Collective learning and its application. In professional learning communities. The major emphasis is on collective learning where individuals learn more than if they are learning independently and all of the community members are involved in that continuous process of learning.

3) Shared personal practice through which members of the community exchange experiences and knowledge. Not only this, but members leave the history of isolation behind and exercise observing, taking notes, discussing, and peer coaching.

4) Shared and supportive leadership with which leadership is dispersed among and between the community members. The power, the authority, and decision making are shared and encouraged.

Once these are the promises that professional learning communities can lend to the reform of education systems in the Arab region and United Arab Emirates system in particular, this gives enough evidence to consider the big ideas of learning communities as a golden key for developing systems of education in these countries.

In its 2009 report about "Knowledge Society in the Arab Region", the United Nation Development Program raised some of the challenges facing Arab countries in constructing knowledge society and the role of education in developing the knowledge capital. The main challenge came in the form of a question: "How to change the systems of education from being conventional graduating individuals to carry out certain specific vocations, to be able to support their societies with learners who have high mental abilities of critical thinking, decision taking, creativity and who can really contribute to development of their communities? Hence questions like; what to learn? How and when to do that?... are to be posed to these systems of education [18]. In spite the big challenges represented in these questions, fortunately PLCs. have a great deal to do with answering those questions and meet the challenges embedded in them. Added to this, there is a growing interest in change and reform of education now overwhelming most of the Arab countries, particularly awareness about implementing education technology to sustain learning and education institutions at all levels.

In this same report of [18] it has been cited that four of the Arab countries came as of the top fifty countries internationally being ready to invest information technology and communication in education. All of the four countries are of the Gulf region and they are United Arab Emirates, Qatar, Bahrain and Kuwait, occupying the international ranks (28, 37, 39 and50) successively. United Arab Emirates got the highest rank amongst the Arab countries and this indicates its capability of implementing its well established infrastructure of information and communication technology in promoting its system of education. In turn this raises the opportunities of facilitating the emergence and rapid growth of learning communities in this country.

\section{CONCLUSION}

The concept of learning communities contains a wide range of theories relating to learning as a process that should be clear for both learners and teachers from the very beginning and that helps achieve the goals of this process. It draws as well on professionalism that refers to a culture of learning including a set of values like cooperation, value of knowledge, and respect between all members of the community towards each other. Added to this the identity that the community looks for and develop all the time. Community again represent a bond which connects all members together while doing the tasks of learning and generate unexpected potentials when adopting the thought of "two heads are better than one and three are better than two". Education and information technology crucially sustain the creation and development of learning communities. At the end of the day, professional learning communities stand over there to tell the story of success for any system of education 
that may manipulate them as an approach for reform. Arab countries including Egypt are suffering from a host of educational problems, out of which and mostly persistent is inadequacy of outcomes of their systems of education. Some lessons from literature and experiences of some countries confirm that implementation of learning communities as an approach for educational reform can help to a great extent to overcome those problems. Accordingly, this paper invites all Arab countries, in particular Egypt, to give attention to construction of learning communities in their schools and universities for that purpose. This initially needs:

1) Schools and universities must be aware that learning is necessary before they can develop into a Learning Community. Learning in this case, represents the base from on which knowledge is to be generated. Accordingly, all the educational institutions after perceiving why to learn, should know exactly what to learn, how to learn and when to learn.

2) Those institutions are required, not only to believe in change but to practice change, since traditional styles of learning are no longer valid for this era of rapid change and intensive use of technology. Once those institutions have excepted the need for change, they are then responsible for creating the appropriate environments for this change to occur in.

3) An adequate technological infrastructure as a crucial factor for establishing those communities. No way to establish a learning community without having a solid base of all kinds of technology that help in accelerating, deepening, and validating the process of learning.

4) A different type of leadership remains a necessity, added to a decentralized system of management. The sort of leadership asked for sustaining learning communities are those leaders who believe in dispersed leadership, who always share thoughts and ideas with all members of the community, and who lead and coach with fatherhood approach. Leaders are who provide commitment for long-term learning in the form of resources. Of course, the amount of resources available (money, personnel and time) determines the quantity and quality of learning. This means that those leaders must be prepared to be fund raisers.

5) Again, strong leadership is vital in implementing professional learning communities and building positive culture of learning. That culture which seems to go through developmental stages to the point whereby norms and values of learning communities become a way of life.

\section{REFERENCES}

[1] S. Kilpatrick, M. Barrett, and T. Jones, "Defining learning communities," Discussion Paper D1/2003, Center of Research and Learning, University of Tasmania, 2003.

[2] D. H. Janssen, C. Kyle, and B. G. Wilson, "Creating technology supported learning communities," Learning with Technology in the
Classroom: A Constructivist Perspective, New York:Prentice Hall, 2004.

[3] The World Bank, The Road Not Traveled: Education Reform in The Middle East and North Africa, University Book House, Al Ain, UAE (Arabic Text), pp. 23-25, 2010.

[4] M. A. Abdeldayem, "Technological education in the Arab world and Israel: A comparative Study," Journal of Education, vol. 2, no. 4, College of education, Zagazig University, Egypt, 1991.

[5] A. A. Alshekhaiby, New Horizons in the Arab Higher Education, Cairo: House of Arab Thoughts, p. 450, 2012.

[6] R. DuFour and R. Eaker, Professional Learning Communities at Work: Best Practice for Enhancing Student Achievement, Alexandria, VA: Association for Supervision and Curriculum Development, pp. xi-xii, 1998.

[7] S. M. Hord and W. A. Sommers, Leading Professional Learning Communities: Voices From Research and Practice, Corwin Press, 2008.

[8] P. Wald and M. Castleberry, Educators as Learners: Creating a Professional Learning Community in Your School, Alexandria, VA: Association for Supervision and Curriculum Development, pp. 9-14, 2000.

[9] S. C. Thompson, L. Gregg, and J. M. Niska. (2004). Professional learning communities, leadership, and student learning. Research in Middle Level Education. [Online]. 28 (1). pp. 1-15. Available: http://www.nmsa.org/Publications/RMLEOnline/Articles/Vol28No1A rticle2/tabid/439/Default.aspx

[10] J. Cothrel and R. L. Williams, "On-line communities: Helping them form and grow," Journal of Knowledge and Management, vol. 3, no. 1 , p. 60,1999

[11] A. W. Asten, Achieving Educational Excellence, San Francisco: Josey-Bass, 1985.

[12] C. Mcloughlin, "Culturally responsive technology use: Developing an on-line community of learners," British Journal of Educational Technology, vol. 30, no. 3, p. 232, 1999.

[13] J. Schacter. (Nov. 1, 2011). "The Impact of Education Technology on Student Achievement. What the Most Current Research Has to Say. Milkenexchange on Education Technology. [Online]. Available: www.milkenexchange.org

[14] Cross, "Introduction to faculty learning communities," New Directions for Teaching and Learning, iss. 97, p. 7, Spring 2004, 1998.

[15] P. E. Calderwood, Learning Community: Finding Common Ground in Difference, New York: Teachers College, Columbia University, 2000.

[16] C. F. Collier, "A Snapshot of the center of Inquiry," Primary Voices $K$-6, vol. 10 , no. 3, pp. 2-7, 2002

[17] S. M. Hord and W. A Sommers, Op. Cit., pp. 8-16, 2008

[18] United Nations Development Program (UNDP) in corporation with Mohammad bin Rashed Al-Maktoom Foundation, Arab Knowledge Society Report, Dubai: UNDP, p. 87, 2009.

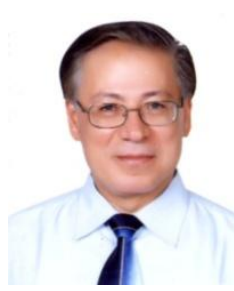

Mohammad Ahmad Abdeldayem was born in Egypt on August 24, 1954. He works as a professor and the chair of International Education and Education Administration Department, at Zagazig university, Egypt. He got his Ph.D. (comparative education) from University of Wales, UK, July 1987. Before getting his M A. in education majoring in comparative administration of Adult Education organizations, Zigzag University, Egypt, June 1983, he got a diploma in education (special diploma) two years full-time courses 1979. His first degree was a BA English language and literature, English Language Department, Zigzag University, Egypt, 1977.

For the last twenty five years, he worked for so many universities in Egypt and some Arab countries like Ajman University in Emirates (1990-1992) Kuwait, (1992-1997), then United Arab Emirates University ( 2002-2006) again (2008-2013). And he was a visiting professor in Saudi Arabia and Sultanate of Oman. During this period he published a lot of research papers and books relating to comparative and international studies on systems of education in so many different countries. He as well participated in a host of other academic activities like attending local, regional and international conferences, supervising and advising master and Ph D students, chief-editor and co-editor of some journals in education. His main interest is in socio-cultural analysis of systems of education in different countries. 